\title{
Mental health of the Mexican population during the COVID-19 pandemic
}

\section{Cristina Rodríguez-Hernández, ${ }^{*}{ }^{*}$ Omar Medrano-Espinosa ${ }^{2}$ and Ariadne Hernández-Sánchez ${ }^{3}$}

${ }^{1}$ Hospital Ángeles Mocel, Mexico City; ${ }^{2}$ Hospital Regional de Alta Especialidad Bicentenario de la Independencia, Instituto de Seguridad y Servicios Sociales de los Trabajadores del Estado, State of Mexico; ${ }^{3}$ Open and Distance University System, Facultad de Estudios Superiores Iztacala, Universidad Nacional Autónoma de México, State of Mexico. Mexico

\begin{abstract}
Introduction: The COVID-19 pandemic has also affected mental health. Objective: To evaluate Mexican population mental health during the COVID-19 pandemic by measuring symptoms of stress, depression, anxiety and insomnia, as well as resilience. Methods: Cross-sectional, descriptive, observational study. A survey was carried out to collect sociodemographic data, and the Depression Anxiety and Stress Scale 21 (DASS 21), Athens Insomnia Scale and the 14-item Resilience Scale (RS-14) were applied. Central tendency and dispersion measures were obtained for quantitative variables and frequencies for qualitative variables. The chi-square test was used for bivariate analysis; alpha level was 0.05 . Results: 1,667 individuals with a mean age of $33.78 \pm 10.79$ years were analyzed. On DASS 21, a mean of 9.7 points (normal) was found, as well as 7.10 for anxiety (normal) and 6.73 for depression (normal). On Athens Insomnia Scale, a mean of 9.33 points (moderate alteration), and on the RS-14 scale, 69.13 points (high resilience) were obtained. Conclusions: Symptoms' intensity was lower than expected in comparison with that recorded in other populations, probably due to the high levels of resilience of the Mexican population.
\end{abstract}

KEY WORDS: COVID-19. Stress. Depression. Anxiety. Insomnia. Resilience.

\section{Salud mental de los mexicanos durante la pandemia de COVID-19}

\section{Resumen}

Introducción: La pandemia de COVID-19 también ha afectado la salud mental. Objetivo: Evaluar la salud mental de la población mexicana durante la pandemia de COVID-19 mediante la medición de síntomas de estrés, depresión, ansiedad, insomnio y resiliencia. Métodos: Estudio observacional, descriptivo y transversal. Con una encuesta se recabaron datos sociodemográficos y se aplicaron la Depression Anxiety and Stress Scale 21 (DASS 21), la Escala Atenas de Insomnio y la Escala de Resiliencia 14 Ítems (RS-14). Se obtuvieron medidas de tendencia central y de dispersión en las variables cuantitativas, así como frecuencias en las cualitativas. En el análisis bivariado se utilizó la prueba de $\chi^{2}$; el nivel alpha fue 0.05. Resultados: Se analizaron 1667 individuos con edad media de 33.78 \pm 10.79 años. En la DASS 21 se encontró una media de 9.7 puntos (normal), 7.10 para ansiedad (normal) y 6.73 para depresión (normal). La Escala Atenas de Insomnio presentó una media de 9.33 puntos (alteración moderada) y la RS-14, 69.13 (resiliencia alta). Conclusiones: La intensidad de la sintomatología fue menor a la esperada en comparación con la registrada en otras poblaciones, probablemente por la alta resiliencia de la población mexicana.

PALABRAS CLAVE: COVID-19. Estrés. Depresión. Ansiedad. Insomnio. Resiliencia.

\footnotetext{
Correspondence: 


\section{Introduction}

In March 2020, the World Health Organization declared COVID-19 as a pandemic; in response, each country's governments dictated sanitary measures aimed at reducing the number of infections among the population, such as isolation or social distancing., ${ }^{1,2}$ These measures were observed as a variable with negative psychological effects with an affective, behavioral and cognitive load. ${ }^{3,4}$

In addition, COVID-19 sanitary alert triggered stressful events such as fear of becoming infected, uncertainty due to the impact on personal finances, xenophobia, excessive exposure to the media (infodemic), exaggerated fear of death and fear of close ones dying, among others. ${ }^{5-7}$ According to the "COVID-19 and the need for action on mental health" policy brief, published by the United Nations, if the impact of this pandemic on world population's mental health is not timely and appropriately addressed, it will turn into a crisis of uncontrollable dimensions. ${ }^{8}$

Studies carried out in different populations around the world have revealed the impact the COVID-19 pandemic has on mental health: on one hand, it activates adaptive mechanisms such as resilience and positive coping and, on the other, it sets maladaptive mechanisms in motion, such as stress, anxiety, depression, sleep and eating disorders, as well as excessive alcohol and tobacco consumption, and suicide. ${ }^{9-19}$

The purpose of this study was to evaluate the mental health of the Mexican population during the COVID-19 contingency by measuring symptoms of stress, depression, anxiety, insomnia and resilience (measured by perceived stress).

\section{Methods}

In order to know the emotional impact the COVID 19 pandemic has on the Mexican population, a survey developed in the Google Forms app was administered during May and June 2020. The instrument consisted of a questionnaire to collect sociodemographic data and data on three scales:

- Depression Anxiety and Stress Scale 21 (DASS 21), to measure the prevalence of symptoms of anxiety and depression and stress severity.

- Athens Insomnia Scale, to measure the prevalence of said symptom.

- 14-item Resilience Scale (RS-14).
Table 1. Prevalence of psychiatric disorders

\begin{tabular}{|l|c|c|}
\hline & n & $\%$ \\
\hline Depression & 609 & 36.3 \\
\hline Anxiety & 632 & 37.7 \\
\hline Obsessive-compulsive disorder & 70 & 4.2 \\
\hline Insomnia & 200 & 11.9 \\
\hline Attention deficit/hyperactivity disorder & 39 & 2.3 \\
\hline Addictions & 41 & 2.4 \\
\hline Personality disorder & 69 & 4.1 \\
\hline Psychotic disorder & 22 & 1.3 \\
\hline Cognitive impairment & 32 & 1.9 \\
\hline
\end{tabular}

This survey was freely sent via different electronic platforms; initially, informed consent was requested from the user for making use of the information for research purposes.

Statistical analysis was carried out with measures of central tendency and dispersion for quantitative variables and frequencies for qualitative variables. In the bivariate analysis, the chi-square test was used. Alpha level was established at 0.05 . The SPSS statistical program, version 21, was used.

\section{Results}

A cohort of 1,667 patients with a mean age of 33.78 \pm 10.790 years and an age range of 18 to 83 years was obtained; $81.6 \%$ of participants were females and $18.4 \%$ were males. The predominant level of education was college degree (50.2\%); as for occupation, professional development prevailed (47.9\%), and predominant marital statuses were single, with $50 \%$, and married, with $40.5 \%$.

With regard to mental health, $58.8 \%$ of the population was found to have had received some type of care in this area sometime in life, either of psychologic or psychiatric nature; the most prevalent pathologies were depression $(36.3 \%)$ and anxiety $(37.7 \%)$, as detailed in table 1.

Regarding the clinimetric scales that were applied, on DASS 21, a mean of 9.7 was found for stress, 7.10 for anxiety and 6.73 for depression, which qualify within normal range. Only in the anxiety subscale were maximum scores found, while maximum scores for depression and stress were found to fall within the range of moderate impairment. On Athens Insomnia 


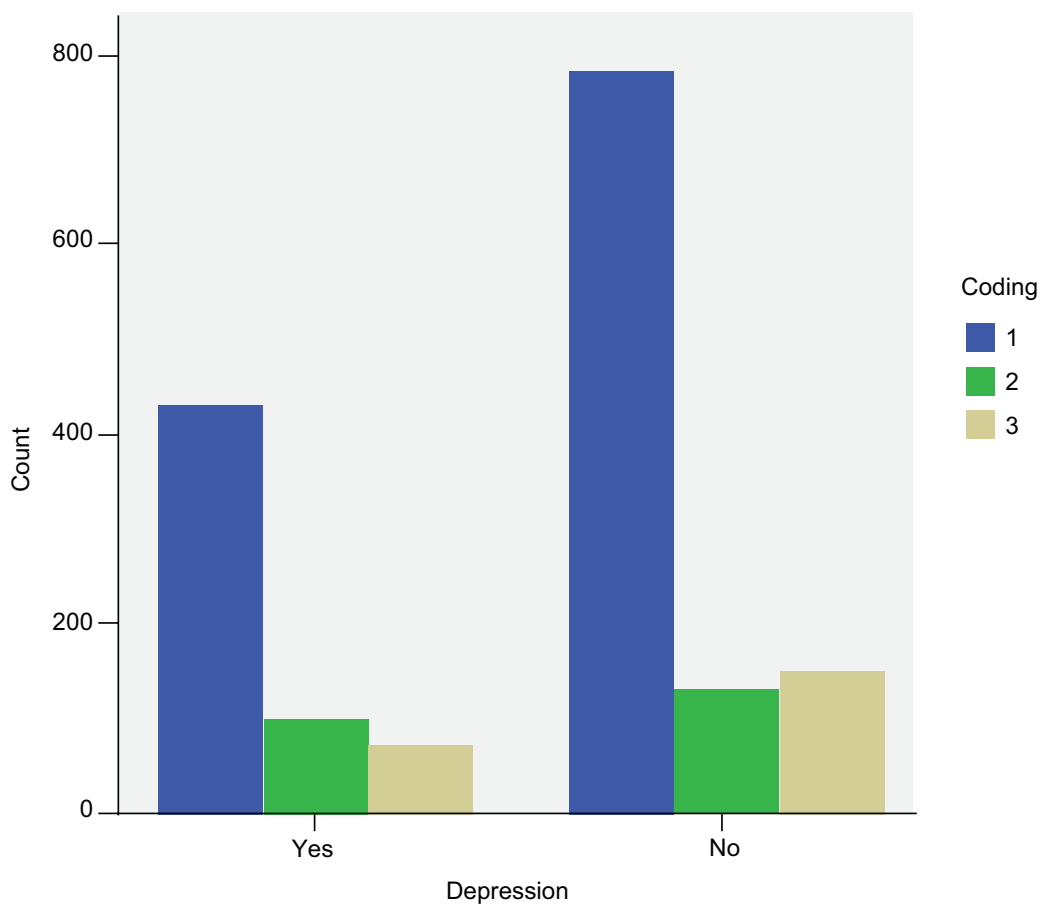

Figure 1. Association between previous history of depression and current symptoms.

Scale, mean score was $9.33 \pm 5.051$ points, indicative of moderate sleep disturbance. On the RS-14 scale, a mean score of $69.13 \pm 19.184$ points was obtained, which corresponds to high resilience (64 to 81 points) (Table 2).

The chi-square test was used to establish associations between previous history and current presence of symptoms; a statistically significant association was found in subjects who had a history of having received care for symptoms of depression, anxiety and insomnia and who during May and June experienced symptoms. The association between stress levels and symptoms of anxiety was not statistically significant (Figs. 1 and 2).

\section{Discussion}

To the best of our knowledge, the results presented in this work are the first obtained with regard to mental health in the Mexican population during the COVID-19 contingency period.

Interestingly, the population is perceived as highly resilient; i.e., it has the capability to flexibly assume extreme situations and overcome them, as shown by the results obtained on RS-14 and that are in agreement with the findings reported by Palomar Gómez,
Table 2. DASS 21 scale

\begin{tabular}{|l|c|c|c|}
\hline & Stress & Anxiety & Depression \\
\hline Mean & 9.70 & 7.10 & 6.73 \\
\hline Median & 9.00 & 6.00 & 5.00 \\
\hline Minimum score & 1 & 1 & 1 \\
\hline Maximum score & 21 & 21 & 18 \\
\hline
\end{tabular}

who describes a high level of resilience in Mexicans. Authors such as Fadah Sandman and González Valdez have found that this resilience is higher in women than in men, which is consistent with the findings of this study. ${ }^{20-22}$

The perceived symptoms of depression, anxiety and stress contrast with those reported in other populations: Ustun mentions that the Turkish population showed higher rates of depressive symptoms during the confinement, which was more evident in women; on the other hand, the anxiety scores were within normal parameters, which differs from observations reported by Salari in the Chinese population, in which an increase of up to $30 \%$ in the incidence of symptoms of anxiety was reported. 23,24

When a comparison was made between patients with a history of anxiety or depressive disorder and 

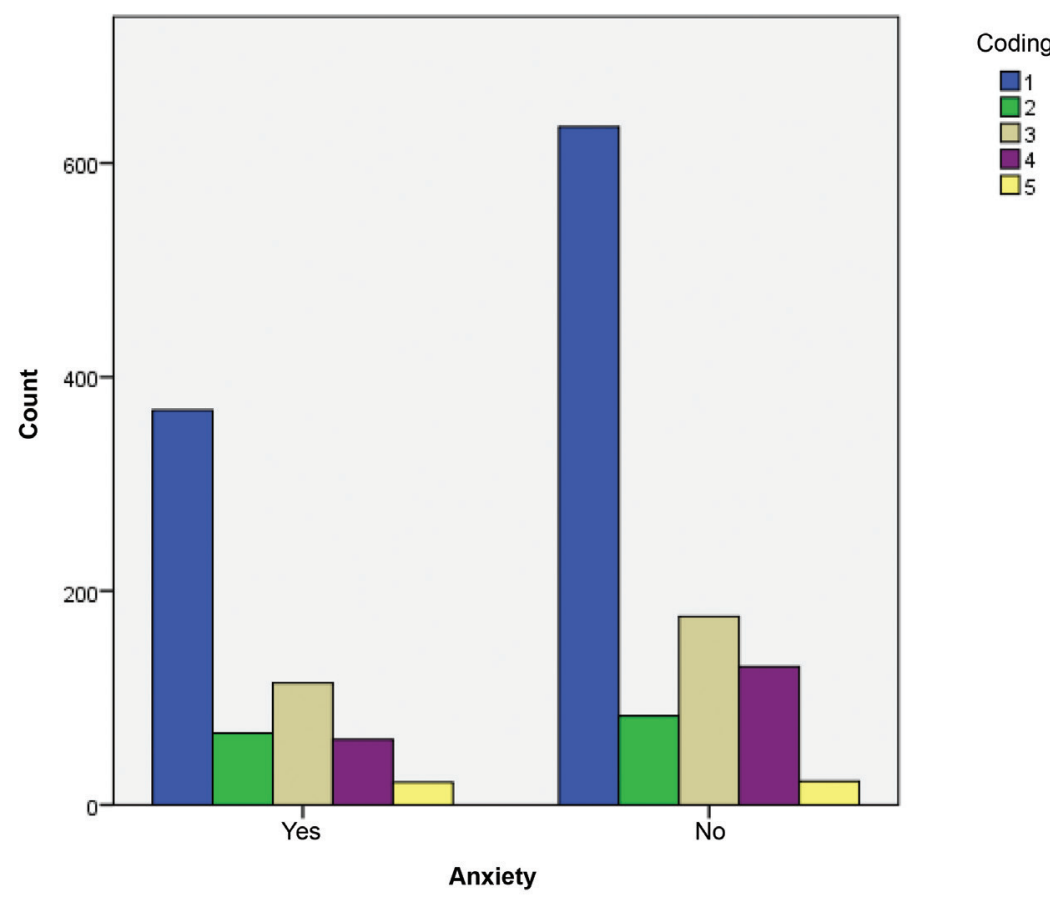

$\square 1$
$\square 2$
$\square 3$
$\square 4$
$\square 5$

Figure 2. Association between previous history of anxiety and current symptoms.

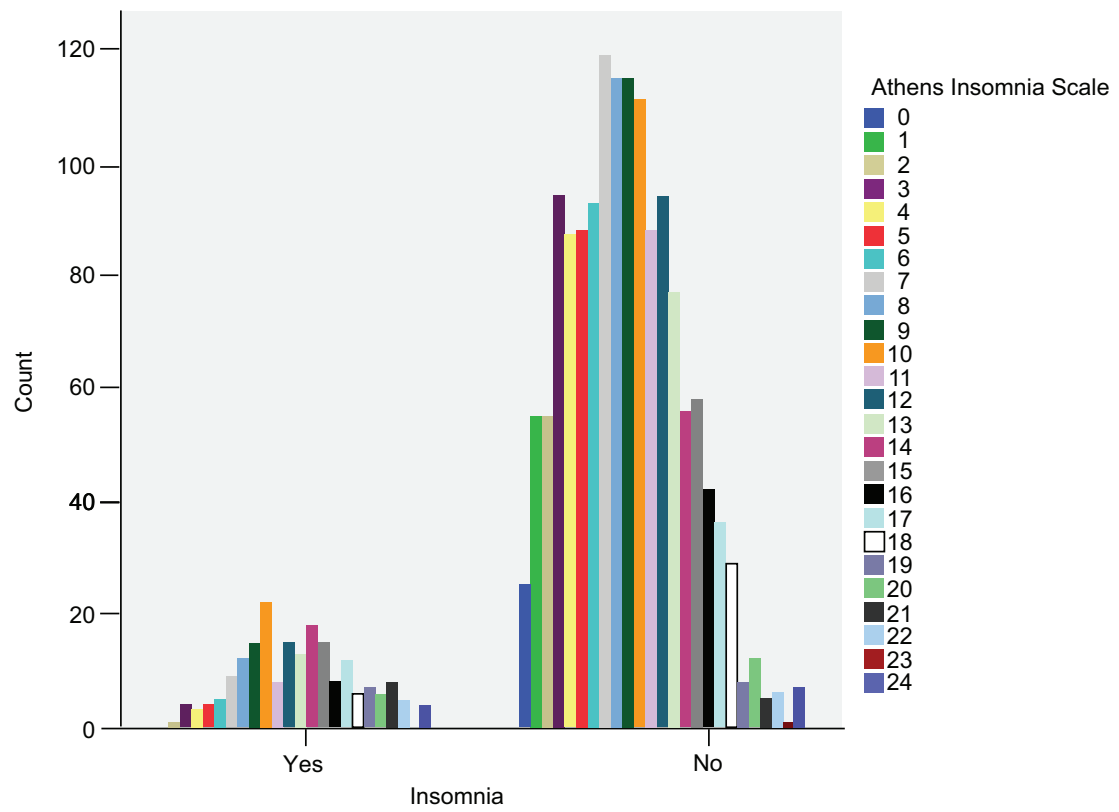

Figure 3. Association between previous history of insomnia and current symptoms.

those who had never been diagnosed, the population without a previous history of diagnosis was observed to have higher symptom scores. This can be explained by three situations:

- The first and most relevant is the concordance with the elevated resilience scores shown by the Mexican population in situations of stress.
- In second place, the limited use of mental health services in the presence of these pathologies. That is, these patients presumably had symptoms before the pandemic and did not receive care.

- Lastly, those who reported a previous condition might have been under treatment, which prevented the severity of symptoms from increasing. 
Finally, regarding the Athens Insomnia Scale, the quality and quantity of sleep were shown to have been seriously affected (Fig. 3). ${ }^{25,26}$

\section{Conclusions}

The COVID-19 pandemic is not only affecting the population's physical health; people's mental health and well-being are also disturbed, which demands priority attention from health specialists. This implies a change in clinical practice in order to allow guaranteeing the care and support of people with previous mental ailments, as well as of the population that starts suffering from the psychosocial consequences of the COVID-19 pandemic. This represents a challenge for the population and health systems in terms of resilience. The generation of evidence-based information will allow detecting the prevalence of repercussions in the domain of mental health of the Mexican population, and thus generate strategies for clinical approach.

It is important pointing out that, in this study, greater repercussions were observed in people who had not previously suffered from any mental health alteration; therefore, information strategies about the most usual symptoms of the most common disorders should be made available, and this way guide the population to be more alert and have self-detection strategies in order for the time between the onset of symptoms and the diagnosis of any mental disorder to be shortened.

\section{Funding}

The authors did not receive any sponsoring to carry out this article.

\section{Conflict of interests}

The authors declare that they have no conflicts of interest.

\section{Ethical disclosures}

Protection of human and animal subjects. The authors declare that no experiments were performed on humans or animals for this research.

Confidentiality of data. The authors declare that no patient data appear in this article.

Right to privacy and informed consent. The authors declare that no patient data appear in this article.

\section{References}

1. Pan American Health Organization [Internet]. USA: Mental health and psychosocial considerations during the COVID-19 outbreak; 2020.

2. World Health Organization [Internet]. Switzerland: Q\&As on COVID-19 and related health topics; 2020.

3. Brooks SK, Webster RK, Smith LE, Woodland L, Wessely S, Greenburg N, et al. The psychological impact of quarantine and how to reduce it: rapid review of the evidence. Lancet. 2020;395:912-920.

4. Rehman U, Shahnawaz MG, Khan NH, Kharshiing KD, Khursheed M, Gupta K, et al. Depression, anxiety and stress among Indians in times of Covid-19. Community Ment Health J. 2020;1-7.

5. Taylor S, Landry CA, Paluszek MM, Fergus TA, McKay D, Asmundson GJG. Development and initial validation of the COVID stress scales. J. Anxiety Disord. 2020;72:102232.

6. Gao J, Zheng P, Jia Y, Chen H, Mao Y, Chen S, et al. Mental health problems and social media exposure during COVID-19 outbreak. PLoS One. 2020;15:e0231924

7. Garfin DR, Silver RC, Holman EA. The novel coronavirus (COVID-2019) outbreak: amplification of public health consequences by media exposure. Health Psychol. 2020;39:355-357.

8. Pan American Health Organization [Internet]. USA: United Nation policy brief: COVID-19 and the need for action on mental health; 2020.

9. Bobo HPL, Chan CLW, Ng SM. Resilience of Hong Kong people in the COVID-19 pandemic: lessons learned from a survey at the peak of the pandemic in Spring 2020. Asia Pacific Journal of Social Work and Development. 2020;31:1-10.

10. Bonanno GA. Loss, trauma, and human resilience: Have we underestimated the human capacity to thrive after extremely aversive events? Am Psychol. 2004:59:20-28.

11. Bonanno GA, Galea S, Bucciarelli A, Vlahov D. Psychological resilience after disaster: New York City in the aftermath of the September $11^{\text {th }}$ terrorist attack. Psychol Sci. 2006;17:181-186.

12. Yuging Z, Yuanyuan A, Xing T, Xiaohui L. Mental health and its influencing factors among self-isolating ordinary citizens during the beginning epidemic of COVID-19. J Loss Trauma. 2020;25:580-593.

13. Huang Y, Zhao N. Generalized anxiety disorder, depressive symptoms and sleep quality during COVID-19 outbreak in China: a web-based cross-sectional survey. Psychiatry Res. 2020;288:112954.

14. Phillipou A, Meyer D, Neill E, Tan EJ, Toh WL, van Rheenen TE, et al. Eating and exercise behaviors in eating disorders and the general population during the COVID 19 pandemic in Australia: Initial results from the COLLATE project. Int J Eat Disord. 2020;53:1158-1165.

15. Stanton R, To QG, Khalesi S, Williams SL, Alley SJ, Thwaite TL, et al. Depression, anxiety and stress during COVID-19: associations with changes in physical activity, sleep, tobacco and alcohol use in Australian adults. Int J Environ Res Public Health. 2020;17:4065.

16. Fitzpatrick KM, Harris C, Drawve G. How bad is it? Suicidality in the middle of the COVID 19 pandemic. Suicide Life Threat Behav. 2020;50.

17. Yao $\mathrm{H}$, Chen JH, Xu YF. Patients with mental health disorders in the COVID-19 epidemic. Lancet Psychiatry. 2020;7:e21.

18. Frank A, Hörmann S, Krombach J, Fatke B, Holzhuter F, Frank W, et al. Psychisch krank in Krisenzeiten: subjektive Belastungen durch $\mathrm{CO}$ VID-19. Psychiatry Prix. 2020;47:267-272.

19. Hao F, Tan W, Jiang L, Zhang L, Zhoa X, Zou Y, et al. Do psychiatric patients experience more psychiatric symptoms during COVID-19 pandemic and lockdown? A case-control study with service and research implications for immunopsychiatry. Brain Behav Immun. 2020;87:100-106.

20. Palomar LJ, Gómez VN. Desarrollo de una escala de medición de la resiliencia con mexicanos (RESI-M). Interdisciplinaria. 2010;27:7-22.

21. Fahad A, Sandman MA. Evaluation resiliency patterns using the ER89: a case study form Kuwait. Social Behav Personality. 2000;28:505-514.

22. González-Arratia-López-Fuentes NI, Valdez-Medina JL. Resiliencia: diferencia por edad en hombres y mujeres mexicanos. Acta Invest Psicol. 2013;3:941-955.

23. Ustun $\mathrm{G}$. Determining depression and related factors in a society affected by COVID-19 pandemic. Int J Soc Psychiatry. 2020;20764020938807.

24. Salari N, Hosseinian-Far A, Jalali R, Vaisi-Raygani A, Rasoulpoor S, Mohammadi $\mathrm{M}$, et al. Prevalence of stress, anxiety, depression among the general population during the COVID-19 pandemic: a systematic review and meta-analysis. Global Health. 2020;16:57.

25. Voitsidis P, Gliatas I, Bairachtari V, Papadopoulou K, Papageorgiou G, Parlapani E, et al. Insomnia during the COVID-19 pandemic in a Greek population. Psychiatry Res. 2020;289:113076.

26. Kokou-Kpolou CK, Megalakaki O, Laimou D, Kousouri M. Insomnia during COVID-19 pandemic and lockdown: prevalence, severity, and associated risk factors in French population. Psychiatry Res. 2020;290:113128. 